\title{
Rehabilitation of the Cardiac
}

\author{
PHILIP R. LEE, M.D.
}

Dr. Lee introduces a provocative approach to the most common form of disability, one which does not lend itself to the usual process of physical repair or vocational training. Public Health Reports will welcome papers dealing with specific applications of Dr. Lee's philosophy.

$\mathbf{R}$ EHABILITATION of the cardiac is a complex process, properly initiated by medical, social, psychological, and vocational evaluation of the patient.

The cardiac may, be an infant with congenital heart disease, a youngster with acute rheumatic fever, a miner with cor pulmonale, an executive with acute myocardial infarction, a farmer with hypertensive cardiovascular disease, or an elderly housewife with chronic rheumatic heart disease. The various etiological types of heart disease must be differentiated in the light of increasing numbers of therapeutic approaches available. For example, the prophylactic use of penicillin to prevent streptococcal infection in youngsters who have recovered from rheumatic fever has prevented recurrent attacks of rheumatic fever and has thus enabled children to live lives nearer normal.

\section{Impairment and Disability}

The patient with heart disease may suffer no disability as a result of his disease or he may be totally disabled. Impairment and disability are often considered to be synonymous, but actually, total disability means the inability to engage in work commensurate with his previous training and his skills and aptitudes, while impairment refers to any structural or functional abnormality. The person who has heart disease may have an impairment of structure or function without disability, or he may be totally disabled with only a minor impairment.

Heart diseases are often associated with a protracted course often with a gradual cumulative impairment, and with a clinical picture that may be complicated by physical, psychological, social, vocational, or economic dislocations.

There may be a short period of severe physical handicap and total disability, followed by complete functional recovery without disability, as in the case of the patient who suffers a heart attack; there may be a gradual progressive downhill course, as in some patients with chronic rheumatic heart disease; there may be a long period of relatively good health with death due to unrelated causes; there may be chronic ill health followed by complete surgical cure, as in many patients with congenital heart disease; or there may be years of little or no handicap terminated by a year or more of increasing ill health and finally death, as in certain patients with severe hypertension. Between the extremes of sudden death and normal life may occur all varieties of physical and functional impairment, as well as physical, psychological, social, and vocational handicap or disability among patients with cardiac disease.

The physical handicaps of the cardiac are most often a diminished tolerance for exercise, easy fatigue, shortness of breath, swelling of the ankles, or anginal pain. Other less common symptoms may occur as a result of heart disease. Psychological handicaps may be greater than the physical. They are likely to take the form of fear of sudden death, anxiety, depression,

Dr. Lee, who has written a number of articles on rehabilitation, is with the Palo Alto Medical Clinic, California. 
overconcern about the heart, hostility or rejection.

Although the great majority of patients with heart disease are able to lead relatively normal lives despite some organic impairment and many are able to work productively in industry, to attend regular school, to labor on the farm, or to carry out the manifold duties of the housewife, any individual with heart disease may be severely handicapped.

\section{Evaluation}

Rehabilitation of the cardiac should begin the moment he is stricken. The first step in this rehabilitation is proper evaluation, including assessment of the physical, psychological, social, and vocational status of the patient. This may be accomplished by the family physician without the aid of the social worker, psychologist, vocational counselor, and consultant cardiologist. If any of the latter are required, however, it is the responsibility of the patient's physician to be sure their services are made available.

It has been estimated that for 80 percent of the cardiac patients evaluation and the management of the total rehabilitation program can be carried out by the patient's personal physician, but for 20 percent of the patients a team approach is essential if the patient is to achieve his maximum level of function in society.

The medical examination should include a careful, accurate, and thorough history as well as a complete physical examination and appropriate laboratory studies. The physician should also assess the patient's functional capacity. The patient may be able to perform the ordinary activities of life without distress, or may find it difficult if he is recovering from an acute cardiovascular illness or if he has many psychological problems which alter his subjective response to exercise.

After the physician has estimated the patient's functional capacity, he should evaluate physical and emotional stresses in the patient's daily life to determine if the patient has the capacity to continue his normal activities. Considerable information is now available for this assessment, not only on the energy cost of a variety of activities, but also on environmental stresses and on the stresses imposed on individuals by their emotional reactions.

Emotional problems are often of greater importance in rehabilitation than the physical limitations imposed on the patient by his disease. The physician can usually determine the major emotional problems if he allows the patient sufficient time to relate the details of his illness, his concerns about himself, his family, job, and future. Occasionally it is necessary to have psychological testing or psychiatric consultation or both.

Of considerable importance in returning a patient to work is the patient's attitude. Jones used a simple method to classify patient's attitudes toward work which he found correlated rather well with success or failure in vocational rehabilitation. The following was his classification. Good: actively seeking employment and cooperative in attempts to help him; fair: willing to work, but doubtful of his ability to do so; poor: not seeking work and maintaining he had difficulty in working; and, bad : obstructing attempts to find him work and claiming his heart made him unfit. Of the patients with a good or fair attitude two-thirds were resettled in productive employment while only one-third of those with a poor attitude and none with a bad attitude were resettled.

If the psychological assets are positive and the patient is strongly motivated, much can be accomplished by the individual, even in the presence of severe organic heart disease. If the patient is not motivated and cannot become so, the physician and other members of the rehabilitation team are likely to accomplish little even if the patient has no physical limitation.

In evaluating the emotional status of a cardiac, especially a child, the patient's family must be considered. Often the family will make the difference between success or failure in rehabilitation. If they are understanding and cooperative they can be of immeasurable aid, but if they are overprotective, fearful, or rejecting, rehabilitation attempts may meet with failure.

\section{Sociologic Factors}

The physical and psychological aspects of cardiac rehabilitation have received considerably more attention than have many of the soci- 
ologic factors despite the latter's importance in rehabilitation. Limitations placed on many cardiacs by their physicians severely restrict their social opportunities as do the employment policies of many industries and the current interpretation and administration of many of our workmen's compensation laws.

When the social and vocational status of any cardiac is evaluated, the fact that the majority of cardiacs can live relatively normal lives should be kept in mind. The majority who labor in industry, on the farm, in the home, or who attend school are better off continuing in their usual work or habits of life than by radically altering them when no clear-cut indication to do so exists.

Points to be emphasized in the social history are the psychological factors to which may be added family relationships, economic status, housing, and education. In the vocational history, information should be obtained on specific characteristics of the job or work place, operations or activities involved, environmental conditions, wages, group pressures or other social pressures on the job, previous vocational experience or training, skill, adaptability, and interests.

For children, appropriate emphasis must be placed on the family, on the child's intelligence, education, interests, motivation, and potential for future activities. In this instance, skill may be developed and patterns established, whereas in older cardiacs often the only realistic approach is to attempt to restore the patient to his usual habits of life and work.

\section{Individualized Planning}

Parallel with the evaluation is the individualization of the rehabilitation program. Although two patients have the same organic defect they will not have the same personality, nor will their habits or environmental stresses be the same. These factors must be considered when giving the patient advice about diet, drugs, physical activity, occupation, recreation, sexual activity, emotional stress, smoking, and the variety of day-to-day problems involved in his rehabilitation.

In what is perhaps the single most important step in the rehabilitation process, the physi- cian's unhurried discussion with the patient about his disease, the emphasis should be on the more optimistic aspects, particularly regarding prognosis and the ability of the patient to return to a reasonably normal and productive life. The patient should be told in some detail how he can best arrange his life to fit the circumstances. Often it is advisable to outline treatment procedures as well as the overall rehabilitation program.

The rehabilitation of any cardiac may involve family members, nurses, teachers, social workers, vocational counselors, psychologists, psychiatrists, surgeons, cardiologists, occupational therapists, dietitians, industrial physicians, employers, union leaders, personnel directors, fellow workers, and friends. Although many disciplines and individuals may be employed in the rehabilitation program, the patient's personal physician must remain his guide from the time of initial illness until the goal of rehabilitation, namely the return of the patient to the best life he can lead with what he has left, is achieved.

\section{Summary}

1. Rehabilitation of the cardiac is a complex process properly initiated by medical, psychological, social, and vocational evaluation of the patient.

2. The rehabilitation program must be individualized to meet the specific needs of the patient.

3. The single most important step in the rehabilitation of the cardiac is the physician's unhurried discussion with the patient about the nature of his disease, its treatment, prognosis, and how he can best arrange his life to fit the circumstances.

4. The rehabilitation of the cardiac may involve many different people, with diverse skills, but the physician must remain the patient's guide until the patient has returned to the best life he can lead with what he has left.

\section{SELECTED READING}

Benton, J. G., and Rusk, H. A. : The patient with cardiovascular disease and rehabilitation. The third phase of medical care. Circulation $8: 417$, September 1953. 
Durbin, E., and Goldwater, L. J.: Rehabilitation of the cardiac patient. Circulation 13: 410, March 1956.

Hellerstein, H. K., and Ford, A. B. : Rehabilitation of the cardiac patient. J. A. M. A. 164: 225, May 18, 1957.

Jones, A. M. : The disabled cardiac. Rehabilitation 15 (N. S.) : 23, Autumn 1955.

Lee, P. R., and Rusk, H. A. : Rehabilitation in industry. Heart Bull. 6: 22, March-April 1957.
White, P. D., Rusk, H. A., Williams, B., and Lee, P. R.: Cardiovascular rehabilitation. New York, N. Y., McGraw-Hill, 1957, 155 pp.

White, P. D., Rusk, H. A., Williams, B., and Lee, P. R.: Rehabilitation of the cardiovascular patient. New York, N. Y., McGraw-Hill. In press.

Wood, H. F., and Lee, P. R.: Physical activity during convalescence of rheumatic fever. Mod. Concepts Cardiovas. Dis. 25 : 361, December 1956.

\section{Revised Regulations for Tuberculous Immigrants}

Aliens with tuberculosis who are permitted to immigrate to the United States are now required to go promptly to a hospital for examination and necessary medical care, according to a change in immigration regulations announced by the Immigration and Naturalization Service of the Department of Justice and by the Public Health Service. Hospitalization as an inpatient is not necessary if the responsible physician determines that outpatient care is adequate. Earlier regulations provided for hospitalization "if required," without stating details on enforcement.

Public Law 85-316 of September 11, 1957, contains a provision permitting an immediate family member of an American citizen or of a resident alien to immigrate to this country although afflicted with tuberculosis. Other aliens with this disease are barred from admission.

Before receiving an immigrant visa, the alien must submit a statement from a State, Territorial, or local health officer, or from the director or a physician staff member of a hospital recognized by the Public Health Service as an institution for the treatment of tuberculosis, agreeing to supply any treatment and observation required for proper management of the alien's condition, in conformity with accepted local standards of medical practice.

This statement must also provide that the United States quarantine station at New York will be furnished a clinical evaluation of the alien, including necessary X-ray films, and a report of final disposal of the case. In each instance the statement of agreement regarding these services must specify the name and address of the hospital at which the services will be provided, and must stipulate that the alien will be given care on an inpatient or outpatient basis when necessary after his arrival at the hospital.

In applying for his immigrant visa the alien must also submit:

- An affidavit from a sponsor or other responsible individual that financial arrangements for the alien's care have been made with the hospital, unless the Dependents Medical Care Act applies.

- Assurance that upon admission into the United States he will go direct to the specified hospital; submit to such examinations, treatment, isolation, and medical regimen as may be required; and remain under the prescribed treatment or observation, whether on an inpatient or outpatient basis, until discharged.

- Assurance that he will comply with the provisions of Sanitary Measures for Travel of Aliens With Tuberculosis. This applies only if the alien's tuberculosis is considered to be in communicable form, in which case he is given a copy of the document.

For purposes of these requirements, the Public Health Service recognizes a hospital as "an institution for the treatment of tuberculosis" if it is listed in Tuberculosis Beds in Hospitals and Sanatoria, Public Health Service Publication No. 518. Copies of this have been sent to State health departments and other local health agencies.

Immigration and Public Health Service officials have expressed the hope that when health departments or qualified private institutions and physicians are called on to provide care for an alien with tuberculosis who is seeking admission to this country, they will carry out the letter of the regulations in order that the spirit of the law may be observed. 